\title{
STABILITY OF CAUCHY ADDITIVE FUNCTIONAL EQUATION IN FUZZY BANACH SPACES
}

\section{HARK-MAHN KIM, ICK-SOON CHANG AND EUnYOUnG SON}

Abstract. In this article, we prove the generalized Hyers-Ulam stability of the following Cauchy additive functional equation

$$
f\left(\frac{x-y}{n}+z\right)+f\left(\frac{y-z}{n}+x\right)+f\left(\frac{z-x}{n}+y\right)=f(x+y+z)
$$

in fuzzy Banach spaces for any fixed nonzero integer $n$.

Mathematics subject classification (2010): 39B52, 46S40.

Keywords and phrases: Fuzzy Banach space, Cauchy additive functional equation, Hyers-Ulam stability, fixed point alternative.

\section{REFERENCES}

[1] T. AOKI, On the stability of the linear transformation in Banach spaces, J. Math. Soc. Japan. 2 (1950), 64-66.

[2] T. Bag And S. K. Samanta, Finite dimensional fuzzy normed linear spaces, J. Fuzzy Math. 11 (2003), 687-705.

[3] T. Bag And S. K. Samanta, Fuzzy bounded linear operators, J. Fuzzy Math. 151 (2005), 513-547.

[4] L. CǍDARIU AND V. RADU, Fixed points and the stability of Jensen's functional equation, J. Inequal. Pure Appl. Math. 4 (2003), no. 1, Art. 4, 7 pages.

[5] S. C. Cheng AND J. M. Mordeson, Fuzzy linear operators and fuzzy normed linear spaces, Bull. Calcutta Math. Soc. 86 (1994), 429-436.

[6] C. Felbin, Finite dimensional fuzzy normed linear spaces, Fuzzy Sets and Systems 48 (1992), 239 248.

[7] P. GǍVRUTA, A generalization of the Hyers-Ulam-Rassias stability of approximately additive mappings, J. Math. Anal. Appl. 184 (1994), 431-436.

[8] O. HADŽIĆ, E. PAP AND V. RADU, Generalized contraction mapping principles in probabilistic metric spaces, Acta Math. Hungar. 101 (2003), no. 1-2, 131-148.

[9] D. H. HyERs, On the stability of the linear functional equation, Proc. Natl Acad. Sci. 27 (1941), 222-224.

[10] G. Is AC AND Th. M. Rassias, Stability of $\psi$-additive mappings, Applications to nonliear analysis, Internat. J. Math. Sci. 19 (1996), 219-228.

[11] A. K. KatSARaS, Fuzzy topological vector spaces II, Fuzzy Sets and Systems 12 (1984), 143-154.

[12] I. KRAmosil AND J. MichaleK, Fuzzy metric and statistical metric spaces, Kybernetica 11 (1975), 336-344.

[13] S. V. KRIShNA AND K. K. M. SARMA, Separation of fuzzy normed linear spaces, Fuzzy Sets and Systems 63 (1994), 207-217.

[14] B. MARGOLIS AND J. B. DiAZ, A fixed point theorem of the alternative for contractions on a generalized complete metric space, Bull. Amer. Math. Soc. 126 (1968), 305-309.

[15] D. Minet And V. RADU, On the stability of the additive Cauchy functional equation in random normed spaces, J. Math. Anal. Appl. 343 (2008), 567-572.

[16] A. K. Mirmostafaee, M. Mirzavaziri and M. S. Moslehian, Fuzzy stability of the Jensen functional equation, Fuzzy Sets Systems 159 (2008), 730-738. 
[17] A. K. Mirmostafaee and M. S. Moslehian, Fuzzy versions of Hyers-Ulam-Rassias theorem, Fuzzy Sets and Syst. 159 (2008), 720-729.

[18] M. S. MosLehIAN AND A. NAJATI, An application of a fixed point theorem to a functional inequality, Fixed Point Theory 10 (2009), 141-149.

[19] C. PARK, Fixed points and Hyers-Ulam-Rassias stability of Cauch-Jensen functional equations in Banach algebras, Fixed point Theory and Appl. 2007 (2007), Art. ID 50175, 15 pages.

[20] V. RADU, The fixed point alternative and the stablity of functional equations, Fixed point Theory 4 (2003), 91-96.

[21] TH. M. Rassias, On the stability of the linear mapping in Banach spaces, Proc. Am. Math. Soc. 72 (1978), 297-300.

[22] S. M. Ulam, A collection of Mathematical Problems, Interscience Publ. New York, 1960.

[23] J. Z. XiAO AND X. H. ZhU, Fuzzy normed spaces of operators and its completeness, Fuzzy Sets and Systems 133 (2003), 389-399. 